\title{
Strategic asset management: A differentiating strategy to enhance a competitive advantage of petrochemical companies
}

\author{
Makama Ephraim Ntlaba, Ozias Ncube* \\ Graduate School of Business Leadership (SBL), University of South Africa, Midrand, South Africa
}

Email address:

72538511@mylife.unisa.ac.za (M. E. Ntlaba), ncubeo@unisa.ac.za (O. Ncube)

To cite this article:

Makama Ephraim Ntlaba, Ozias Ncube. Strategic Asset Management: A Differentiating Strategy to Enhance a Competitive Advantage of Petrochemical Companies. International Journal of Business and Economics Research. Vol. 3, No. 3, 2014, pp. 118-127.

doi: 10.11648/j.ijber.20140303.11

\begin{abstract}
This paper presents the results of a study of the benefit of implementing Strategic Asset Management (SAM) in line with principles recommended by PAS 55. SAS can assist organisations in the petrochemical industry to enhance their competitive advantage and subsequently become profitable. A survey design methodology is employed in this study. Four business sites of the case under study in South Africa, ranging from maintenance to production disciplines were sampled. Data is collected using questionnaires that were distributed to the four manufacturing sites, and 63 responses were received. Data mining was also conducted on SAP for the determination of seven KPI's (Key Performance Indicators). The results reveal that the majority of the KPI's are below target. This indicates deficiencies as far as effective SAM is concerned. This is also an indication of instability in operations resulting in inability to consistently and sustainably supply the market. Most respondents believe that SAM is the responsibility of all the members of the supply chain, and also that discipline cohesion, equipment reliability, pro-active maintenance, plant stability and safety are fundamental drivers of implementing SAM and condition monitoring. During the implementation process the significantly affected factors were observed to be operations, maintenance practices and employees. Management of the change and time presented challenges during the implementation process. Risk identification techniques and risk management techniques such as root cause analysis (RCA), failure modes effects and criticality analysis (FMECA), on-line condition monitoring and reliability centred maintenance (RCM) are the most preferred techniques. Results reveal that the majority of the employees are not familiar with PAS 55 and they believe it cannot be sustained. To support SAM, adherence to OEM instructions and competency of maintenance contractors are revealed to be the most important factors. Maintenance costs and SAP based KPI's can be used to indicate the success of SAM. The main limitation of the study is that sampling was confined to a specific location's facilities and therefore results cannot be generalised.
\end{abstract}

Keywords: Asset Management, Competitive Advantage, Key Performance Indicators, Reliability, Availability, Plant Stability, Sustainability

\section{Introduction}

Organisations in the petrochemical industry are capital intensive; these organisations extensively rely on physical assets in their operations to deliver on their strategic mandate. These operations encompass three fundamental imperatives that collectively seek to maximise value derived from their physical assets in order to increase production volumes - sweating of assets; creating value for owners by generating income, increasing the value of assets, and securing the income and value of the business.
Equipment reliability, equipment availability and plant stability are fundamental components in effectively sweating assets and deriving the maximum value out of them. Despite various interventions and initiatives employed by the petrochemical organisations to ensure sustainability and profitability of their businesses, the maintenance costs are continuously raising due to business dependency of physical assets, equipment reliability and availability are under pressure as a result of "driving" the assets too hard and this subsequently results in plant instabilities. This phenomenon has presented a challenge to 
organisations to develop and consider options on how to effectively and efficiently counter these challenges.

Wireman (2005) observed that most organisations do not have exclusivity in their assets and processes when producing and providing a product to the market. In most cases, organisations in the petrochemical industry use the same raw material and same type of assets for production, therefore, the only way great companies can differentiate themselves from their competitors is the manner in which they manage their physical assets.

The implementation of Strategic Asset Management (SAM) principles in line with PAS 55 recommendations is an option that has been selected to manage assets, with specific reference to paragraph 4.3.3 - Asset Management plans, in order to derive maximum benefit from these assets through improved reliability and availability of equipment, as well as stable operations and a higher return on assets (ROA).

Maintenance is a major production cost and today's global competitive landscape has placed an enormous pressure on businesses to be financially stable. This research aims to develop a motivation to management of the business case under study that SAM facilitates derivation of maximised asset benefits which ultimately gives a business within the petrochemical industry a competitive advantage. The current status of the organisation's business is evaluated, and the level of knowledge of operations personnel (maintenance and production) on asset management is also investigated. This is achieved through field survey that is conducted on four business units. KPIs are also evaluated through the analysis of the SAP data obtained from the organisation's system.

The organisation occupies 60 per cent of the local market and 30 per cent is currently occupied through imports. The biggest contributing factor of high imports is the instability of the manufacturing plants. This instability impedes the organisation's capability of supplying the customers at a consistent and reliable rate. Consequently, this drives customers to seek alternative suppliers internationally; hence the 30 per cent market occupation by the international suppliers. The instability of the manufacturing plants emanate from unreliability and unavailability of the equipment.

Existing lack of confidence among the customers towards the ability of the organisation resulted in the company losing its competitive advantage and subsequently losing a significant share of the market. The implementation of PAS 55 Asset Management principles seeks to improve the competitive advantage of the organisation. This is expected to generate opportunities for expansion of the market share through restoring customer confidence and hence subsequently discourage imports.

Properly managing physical assets is of utmost importance as this will increase equipment reliability, equipment availability and subsequently, plant stability. The subsequent benefit of this is an enhanced competitive advantage of a business on the basis of reliable, consistent and sustainable supply.

The following research question guided the investigation:

Does the effective implementation of asset management principles result in competitive advantage and profitability for an organisation?

This research question is operationalized by the following research propositions;

\section{- Proposition 1}

Strategic Asset Management results in reliable assets that contribute to improved plant availability.

\section{- $\quad$ Proposition 2}

Improved plant availability results in stable operations that sustain product supply to the market.

\section{Methodology}

This is a structured causation research with the objective of identifying the effects of Strategic Asset Management implementation as per PAS 55 guidelines with regard to enhancing organisations' competitive advantage through;

- Improved asset reliability,

- Asset availability and

- Plant stability

A gap analysis is first conducted. This analysis entails evaluating the level of compliance to the asset management principles. The Key Performance Indicators are studied for this purpose. The understanding and opinions of operations personnel (Artisans, Trade Managers, Shift Managers, Planners, Section Leaders, Reliability Engineers, Production Managers, Engineering Managers and Operations Managers) on principles of Strategic Asset Management as well as their opinions on these principles are tested through a survey instrument.

\subsection{Research Design}

According to Leedy and Ormrod (2010), a descriptive quantitative research involves identifying the characteristics of an observed phenomenon; it is further asserted that this type of research often involves collecting information through data review, surveys, interviews, or observation. Descriptive research describes the way things are.

To achieve the research objective and to address the research question, a descriptive analysis of exploratory nature is employed. Quantitative data is collected and analysed in an attempt to gain insights and familiarity pertaining to the state of asset management as perceived by employees. The exploratory approach seeks to identify patterns and perceptions to strengthen the recommendations for implementation of Asset Management.

Leedy and Ormrod (2010) define triangulation as the process of using multiple sources of data with the hope that data will converge to demonstrate consistency and support the recommendations to implement Asset Management principles. 
Data collection was done using two methods applied in parallel; the first method was to collect data through questionnaires, as shown in appendix $\mathrm{A}$, and the second method entailed gathering information pertaining to KPI's from the SAP system. This was done for triangulation purposes.

\subsection{Assumptions}

The following assumptions are made in order of contextualising the study:

- The respondents participating in this research represent the population of organisation's employees and therefore their feedback gives the reflection of the entire organisation.

- The respondents hold senior positions within the organisation, from artisan level upward, they are therefore capable of providing strategic perspective regarding physical asset management.

- The respondents have some engagement with the physical assets, either through maintenance or operations.

- The respondents took reasonable amount of time to read, understand and answer the questions properly.

- $\quad$ CMMS (Computerised Maintenance Management System) exists and are functional in the organisation. This is used to extract data on key performance indicators (KPI's) to determine the level of compliance.

\subsection{Delimitations}

- To achieve the organisational strategic imperatives, the five categories of assets that should be holistically managed are: human assets, financial assets, information assets, intangible assets and physical assets. The focus of this study is on Physical assets, which entails equipment and machinery applicable to the manufacturing process in the organisation's business.

- The study is limited to the development of a motivation to the management of the organisation to implement an asset management program which will assist in effective management of physical assets. This will subsequently enhance the business competitive advantage; The study does not evaluate the benefits post the implementation of Strategic Asset Management principle as prescribed by PAS 55.

\subsection{Sampling}

The target population for this study is the manufacturing sites of organisation in South Africa, with specific emphasis on employees in maintenance and production. Following the discussion with the management of the organisation, four manufacturing sites were identified to participate in the study.
Diamantopoulos and Schlegelmilch (2000) define nonprobability sampling as the sampling procedure where the selection of the sampling elements is left to the discretion of the researcher and there is no explicit scientific model which can be used to assess the degree of sampling error.

Quota sampling is a method of a non-probability sampling procedure, the selection criteria of quota sampling is "sample members are chosen on the basis of satisfying some pre-specified criteria thought to apply to the population; the researcher is free to choose which elements to include in the sample as long as they qualify on the pre-defined characteristics." Diamantopoulos and Schlegelmilch (2000: 14)

The sampling method used in this study is the nonprobability sampling, with specific reference to quota sampling. This method conforms to the preceding definitions in that the sample members conform to predefined criteria; personnel having some engagement with the physical assets through either maintenance or production. Furthermore, sample members occupy predefined positions within these two functions; Artisans, Trade Managers, Shift Managers, Planners, Section Leaders, Reliability Engineers, Production Managers, Engineering Managers and Operations Managers.

All the sampled members have vested interests in the well-being of the assets since they are all responsible for the manufacturing facilities. In this regard, the sample can be considered to be homogeneous. Diamantopoulos and Schlegelmilch (2000) argue that homogeneous sampling results in less degree of variability.

Out of the operations population of 73 personnel, a sample size of 62 was determined.

A parallel approach was also undertaken that entailed gathering information on the level of compliance to seven key performance indicators (KPIs). Gathering and codifying data into information was achieved through visits to planning departments of the manufacturing sites identified, where data mining was performed from SAP.

\subsection{Measuring Instruments}

The questionnaire consists of 66 questions that are divided into 4 categories; category A concentrates on biographical information of the respondents, category $\mathrm{B}$ concentrates on general issues pertaining to Asset Management, this category is further sub-divided into five sub-categories. Category $\mathrm{C}$ deals with issues that are identified specifically for Asset Management, this category is further sub-divided into six sub-categories. The last category of the questionnaire is category $\mathrm{D}$, this category deals with PAS 55 and it is further sub-divided into two categories.

This study deals with complex constructs relating to personnel opinions, attitudes and perceptions about the status of Asset Management understanding and implementation as prescribed by PAS 55 .

Three types of measurement scales were used in this study to capture the responses; 
- Determinant choice - respondents are given various options and requested to select only one.

- Dichotomous scale - this scale requires the respondents to respond with a simple yes or no.

- Likert scale - Here the respondents are asked to indicate a degree of agreement and disagreement with series of statement each.

\subsection{Data Analysis}

IBM SPSS statistical software was used to analyse the data collected from the individual respondents. The four manufacturing sites are not analysed individually, the analysis is done for the business as a whole and results are presented as such.

Data that was collected via the questionnaires was coded for ease of analysis and interpretation of results;

- The "determinant choice" part of the questionnaire was coded with numerical values from 1 to 4 ; this coding does not represent any particular order of importance of the responses.

- The "dichotomous scale" part of the questionnaire was also coded with numerical values of 1 and $2 ; 1$ representing a 'yes' and 2 representing a 'no'.

- The "Likert scale" part of the questionnaire was predominantly code with values of 1 to 4 , only a small part was coded with values of 1 to 5 , the coding of this scale in a particular order of significance; lower number representing less significant and higher number representing higher significance.

\subsection{Reliability and Validity}

Diamantopoulos and Schlegelmilch (2000) define reliability of a measure as the extent to which a measurement is free from variable error; they also define validity of the measurement as a degree in which a particular measure is free from bias and variable error.

"The extent to which results are consistent over time and an accurate representation of the total population under study is referred to as reliability and if the results of a study can be reproduced under a similar methodology, then the research instrument is considered to be reliable." (Golafshani, 2003: 598)

Golafshani (2003) further attests that validity determines whether the research truly measures that which it was intended to measure or how truthful the research results are.

History has shown that Sasol Polymers employees do not like to spend considerable time on questionnaires and they are reluctant to participate in open-ended questions, to accommodate this reluctance, a very simple close-ended questionnaire was developed and this improved the employees' eagerness to participate in the study.

Also as a front-end loading in facilitating the reliability and validity of the research, a number of briefing sessions were held with the target groups of the manufacturing sites; these sessions afforded participants the opportunity to seek further clarity on uncertain issues that might compromise the success of the research in terms of reliability and validity.

\subsection{Ethical Consideration}

Leedy and Ormrod (2010: 101) suggest that whenever human beings or other creatures with the potential to think, feel, and experience physical or psychological distress are the focus of investigation, it is important to look closely at the ethical implications of what is proposed to be done.

To adhere to the prescribed ethical considerations during this research, the following were undertaken;

- Permission to execute the research was request and granted by the operations managers of the manufacturing units.

- Participants were briefed and all uncertainties clarified.

- $\quad$ Participation was strictly voluntary.

- Participants were not misled in anyway during the briefing sessions and during the research.

- Participants and their manufacturing sites were guaranteed privacy and anonymity - this is evident from the fact that there is not participant's name and manufacturing site in the questionnaire.

\section{Research Findings}

The investigation and data collection was conducted in two steams; stream one entailed gathering data from the SAP system of the four manufacturing site, and the second stream was conducted through the Asset Management questionnaires to employees.

The data collected through stream one was fed into the excel spread sheet and the average of the four manufacturing sites was used answer the research question and draw conclusions on the proposal.

\subsection{Stream 1-KPI's - Developed from SAP}

\begin{tabular}{|c|c|c|c|c|c|c|c|c|}
\hline Maintenance KPI's & Keys & Jan-12 & Feb-12 & Mar-12 & Apr-12 & May-12 & Jun-12 & 6 Months Average \\
\hline Backlog Status - Weeks & Betreen $1 * 3$ & 2.9 & 2.9 & 4.2 & 3.0 & 2.4 & 1.0 & 1.4 \\
\hline $\begin{array}{l}\text { \% Emergency Ratio - Hours } \\
\text { [Target 5\%] }\end{array}$ & $5-7 \%$ & 9.0 & 32.0 & 21.0 & 33.0 & 25.0 & 7.0 & 10.6 \\
\hline $\begin{array}{l}\text { \% Urgent Ratio- Hours } \\
\text { (Target 10\%) }\end{array}$ & $\frac{315 \%}{10-15 \%}$ & 20.0 & 6.0 & 13.9 & 7.2 & 5.9 & 21.0 & 6.2 \\
\hline $\begin{array}{l}\text { Schedule Attainment - Count } \\
\text { (Target 80 - 9096) }\end{array}$ & $\begin{array}{l}60-8 \% \% \\
80-90 \% \\
30-10 \% \% \\
100 \%\end{array}$ & 63.0 & 37.0 & 84.4 & 87.6 & 87.9 & 72.9 & 36.1 \\
\hline $\begin{array}{l}\text { Actual vs. Plan on Scheduled work } \\
\text { - Hours (Target 80 - 90\%6) }\end{array}$ & & 82.6 & 59.0 & 75.7 & $\mid 127.0$ & 81.7 & 69.8 & 41.3 \\
\hline $\begin{array}{l}\text { Capacity Planning - Hours } \\
\text { (Target 80\%) }\end{array}$ & $\begin{array}{l}\frac{50-60 \%}{60-85 \%} \\
85-100 \% \\
100 \%\end{array}$ & 30.0 & 57.3 & 57.0 & 48.6 & 57.0 & $\mid 66.0$ & 26.3 \\
\hline $\begin{array}{l}\text { PM Attainment - Count } \\
\text { (Target 9056) }\end{array}$ & $\begin{array}{r}60-80 \% \\
80-90 \% \\
90-100 \% \\
100 \%\end{array}$ & 78.4 & 30.0 & 27.8 & 77.0 & 66.0 & 79.0 & 29.8 \\
\hline
\end{tabular}

Figure 1. Maintenance KPI's - 12 months rolling average (Targets adopted from SAMICORP). 
Figure 1 depicts the backlog of 1.4 weeks for the four manufacturing plants for the period of six months as compared to the benchmark value of 4 weeks. This can be attributed to inadequacies in executing preventive maintenance inspections and over staffed maintenance team and this negatively impacts reliability of the equipment. These inadequacies are contrary to the principles of SAM as suggested by Faiz and Edirisinghe (2009) that a typical asset management system observes assets for signs of failure or degradation and schedules maintenance intervention before critical failure occurs.

It is also illustrated in Figure 1 that the average percentage emergency ratio and the urgent ratio is 10.6 and 6.2 respectively; this means that 10.6 per cent and 6.2 per cent of the total man-hours available for the four manufacturing sites is spend dealing with emergencies and urgent jobs, this high emergency and urgent ratios leave no room for preventive maintenance principles to be implemented. The high emergency and urgent ratios cost the business more than planned activities; this is supported by Hastings (2010) in saying that the cost of failure is generally high when compared with the costs of planned maintenance, repair and replacement strategies.

Hastings (2010) further argues that reliability is important because failures reduce the effectiveness of production and compromises the organisational strategic intent which the assets are intended to support. High emergencies and urgent mode of operation emanates from unreliable equipment breaking randomly.

Figure 1 also shows schedule attainment of 36.1 per cent is achieved, this effectively means that only 36.1 per cent of the work orders was completed during the analysis of the six months as, this is way below the acceptable figure of between 80 and 90 per cent. The low schedule attainment figure can be linked to the high emergency and urgent ratios; the reactive mode of operation results in less time to execute scheduled activities and hence the low schedule attainment.

According to Horner, El-Haram \&Munns (1997), preventive maintenance was introduced to reduce the probability of occurrence of failure and to avoid sudden failure. He further argues that this strategy is referred to as time-based maintenance, planned maintenance or cyclic maintenance. Preventive maintenance tasks are performed in accordance with a predetermined plan at regular, fixed intervals.

Figure 1 depicts "Actual vs. Plan on Scheduled Work hours" of 41.3 per cent; this means that only 41.3 per cent of the planned maintenance hours are achieved, the industry benchmark is 90 per cent and any value between 80 and 90 per cent is acceptable.

This key performance indicator shows that the maintenance planning of the manufacturing sites of Sasol Polymers is not effective; available man hours are planned, however, only 41.3 per cent of those hours are realised. This is also attributed to the existing reactive mode of operation.
Safi and Mozar (2004)observed that in a typical reactive system, significant maintenance efforts are invested in responding to breakdowns. The unpredictable and random nature of breakdowns does not allow work to be planned.

The above observations by Safi and Mozar (2004) are also evident from low PM Attainment of 29.8 per cent indicated in Figure 1.This value effectively translates into only 29.8 per cent of the total preventive maintenance strategy work orders being executed, resulting in random unmanageable breakdowns and ultimately resulting in reduced equipment lifespan.

These observations are further aligned to Faiz and Edirisinghe (2009) when they mention that a typical asset management system observes assets for signs of failure or degradation and schedules maintenance intervention before critical failure occurs.

The average capacity planning for the organisation is 26.3 per cent; this indicates that only 26.3 per cent of the total available man-hours are planned and accounted for, and this constitutes a significant shortfall in properly managing resources and utilisation thereof.

\subsection{Stream 2 - Questionnaire}

The second stream deals with the employees' perceptions and beliefs in relation to the status of asset management in the four manufacturing sites.63 employees responded to the questionnaires and the responses were inputted into SPSS for analysis. This perception stream is classified into categories as illustrated in figure 2 below.

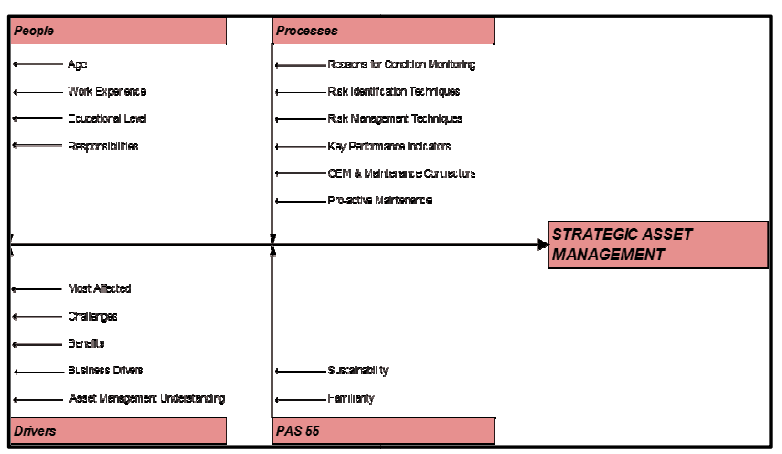

Figure 2.Study Hierarchy.

\subsection{People}

It is widely believed that asset management is an isolated function within the business. Part of the questionnaire aimed to identify the perception of respondent in relation to the ownership of asset management.

Majority of the respondents believe that asset management is for everyone in the value chain, this perception is in alignment with the definition made by Faiz and Edirisinghe (2009) that asset management is a process of identification, design, construction, operation, and maintenance of physical assets. This clearly demonstrates that every stage of the supply chain is involved in asset management, from design through to disposal. 


\subsection{Business Drivers}

Respondents were also tested on what they believe to be the most important among the identified business drivers. The research indicates that respondents believe that the following business drivers, in order of their importance, are the most important;

$\checkmark \quad$ Safety

$\checkmark \quad$ Plant stability

$\checkmark \quad$ Sustainability

$\checkmark \quad$ Plant availability

$\checkmark \quad$ Equipment reliability and

$\checkmark$ Production volume.

The findings above are concurred to by Moubray (2007) when he suggests that Reliability-Centred Maintenance (RCM) seeks to achieve, among others, the following;

$\checkmark$ Greater safety and environmental integrity $-R C M$ considers the safety and environmental implications of every failure mode.

$\checkmark \quad$ Improved operating performance (output, product quality and customer service) - RCM recognises that all types of maintenance have some value, and provides guidance in deciding which is the most suitable in every situation.

$\checkmark$ Greater maintenance cost-effectiveness - RCM focusses on the maintenance activities which have the most effect on the performance of the plant.

$\checkmark \quad$ Longer life-span of assets

Successful implementation and sustainability of asset management is dependent on employees believing in benefits this phenomenon has on the business as well as individuals. It is revealed that majority of the employees believe that discipline cohesion (bringing the different organisation disciplines closer together) is the most important benefit of implementing Asset Management processes.

Further to discipline cohesion stated above, the research also reveals that employees believe that the following, in the order of their importance, are also the important benefits of implementing Asset Management processes;

- Improved decision making

- The organisation learning experience during the implementation process

- Enhanced systems thinking in terms of equipment life cycle view

- Becoming the learning organisation (continuous improvement)

- Process transparency

It is clear from above that employees believe there are benefits in implementing the processes of asset management.

To succeed in implementing and sustaining asset management, obstacles and challenges should be identified and eliminated. This section seeks to identify and understand what employees believe and perceive to be the main challenges that negatively impact the implementation of asset management.

Majority of the respondents suggest that time constraints (getting time of the required resources) presents a considerable challenge in implementing asset management, the respondents further identified the 'management of change' as another factor that presents a significant challenge.

In order to be able to take precautions in safe-guarding the successful implementation of asset management, it is imperative that aspects that are most affected be identified and the degree of effect be understood.

The research indicates that respondents believe that 'operation and maintenance practices - changing mind-sets and behaviours' is the most affected aspect when implementing asset management; the research further reveals that employees are also believed to be the most affected during the implementation of asset management.

\subsection{Business Processes}

Condition monitoring program plays a fundamental role in the asset management program, this ensures that potential failure are identified before they actually develop into defects - a predictive approach. This particular analysis seeks to identify how familiar employees are with the phenomenon of condition monitoring.

"Reliability Centred Maintenance (RCM) is an evolutionary approach to equipment reliability. It focusses on optimisation of preventive and predictive maintenance programs to increase equipment efficiency (uptime, performance and quality) while minimising the related cost." Wireman (2005: 165)

The analysis shows that the respondents believe that the following are the most important reasons to implement condition monitoring;

- Improved equipment reliability

- Increased ratio of pro-active versus reactive maintenance

- Optimised timing for planned outage

It is also shown in the analysis that 'improved decision making' and 'reduced maintenance cost' are also important, but not to the same degree as the ones mentioned above.

The employees were also requested to share their understanding of the risk identification techniques; they were requested to rank the importance of the techniques.

The analysis indicates that majority of the respondents believe that preventing repeat failures (root cause analysis) is the most important technique. Equipment failures negatively impact plant availability and stability; this is evident from the reactive nature of the business as depicted in Figure 1.It is further indicated that the second most important technique is believed to be FMECA (failure mode effect criticality analysis); this technique facilitates the development of maintenance strategies, which is the fundamental concept in implementing effective asset management. 
Faiz and Edirisinghe (2009) also suggest that the predictive maintenance concept recognises that a change in condition and performance of an item is the principal reason for carrying out maintenance. Thus, the optimal time to perform maintenance is determined from a condition survey used to determine the actual state of each asset.

To support the suggestion given above, the research shows that employees believe that on-line condition monitoring is the most important risk management technique; this is in conformance with the observations made by Faiz and Edirisinghe (2009) that predictive maintenance is an essential component of asset management systems. On-line condition monitoring is an asset management regime that helps in identifying potential failures before they develop into actual failures.

It is further indicated that the second most important risk management technique is the RCM (reliability centred maintenance).This technique is defined by Campbell and Reyes-Picknell (2006) as a method used to determine the most appropriate maintenance policy in support of asset management.

The following Key Performance Indicators were identified as important in effectively implementing and sustaining asset management;

- OEE - Overall equipment effectiveness

- $\quad$ SAP based KPI's - as depicted in Figure 1

- Maintenance cost

- Percentage of Maintenance cost to Asset replacement Value

Key Performance Indicators (KPI's) are an important management tool to measure business performance, and are often used to measure maintenance. It is often said that "what gets measured gets done." (Reliability Tips, 2007)

The respondents believe that all the four KPI's are important in facilitating the success and sustenance of asset management.

Effective equipment maintenance is a fundamental component of the asset management program, it is logical to assert that the original equipment manufacturers (OEM's) of the equipment are the most qualified in terms of prescribing maintenance plans. It is therefore imperative that the manufacturers' data books detailing the maintenance plan be part of the 'end of job' documentation.

It is also imperative that OEM's responsibility extends beyond the point of delivery; the OEM should avail the 'after sale' technical support at operation stage of the equipment.

Employees believe that 'OEM maintenance instruction', 'OEM data books' and 'OEM technical support' are important towards ensuring that effective asset management is implemented and sustained.

The research also indicates that the employees also believe that 'Maintenance contractor technical capabilities', 'Maintenance contractor knowledge transfer' and 'Maintenance contractor service level contracts' are also important.
It is inevitable that the business will occasionally make use of the services of the maintenance contractor, it is therefore imperative that the service level contract exists with the maintenance contractor; this will ensure that the technical capabilities of the contractor are prescribed, well managed and utilised. The service level contract will also assist in ensuring that knowledge transfer is prescribed and formalised.

In assessing the status of the organisation in terms of pro-active maintenance, the assessment revealed that majority of the respondents affirmed that less than 60 per cent of the maintenance activities are pro-active. It also revealed that maintenance cost spent on pro-active maintenance is less than 60 per cent. These values collaborate the findings depicted in Figure 1 showing high percentages of emergency ratio and urgent ratio. The organisation's resources are invested predominantly in reactive maintenance.

\subsection{PAS 55}

63 employees participated in the research. This section seeks to identify how conversant or familiar the respondents are with regard to PAS 55. The following is the outcome:

$\checkmark \quad 38.1$ per cent of the participants have never heard of PAS 55

$\checkmark \quad 23.8$ per cent know about PAS 55 but have never read it

$\checkmark \quad 25.4$ per cent have read PAS 55 but do not understand it

$\checkmark \quad 12.7$ per cent of the respondents are comfortable with PAS

The employees were further tested on how optimistic they are with regard to the sustainability of PAS 55 in the asset management arena. The test revealed that 63.5 per cent of the respondents are not convinced that PAS 55 is sustainable in the asset management arena; they believe that PAS 55 is just a 'flavour of the month'.36.5 per cent of the respondents believe that PAS 55 is here to stay.

\section{Conclusions}

Based on the results and findings of this study, the following conclusions may be drawn;

- It is clear from the study that the benefits of the SAM are eminent; this was observed from the theoretical/perception aspect as well as the field-work done on this subject in compiling the KPI's.

- Management buy-in and involvement in the implementation and execution of this process is imperative. Operational employees require leadership and guidance in the implementation of this program. This will ensure the elimination of obstacles that might undermine the effectiveness of the process and have detrimental effect to employees' perceptions about the process. 
- $\quad$ Poorly managed physical assets result in instability of the operations and this is clear from the KPI results. It can then be concluded that unstable operations are obstacles to constant and reliable supply of product to the market, this results in consumer sourcing alternative suppliers, hence the organisation's occupation of 60 per cent of the South African market.

- 30 per cent of the South African market if occupied by international producers; this presents a huge opportunity for growth for organisation's business in terms of expanding the market share. Effectively implementing asset management will improve stability of operations and ensure the reliability of the product supply, and subsequently boost the market confidence.

- The results indicate that even though they may not be aware of PAS 55, the employees believe in some of the asset management principles prescribed by PAS 55.This will assist in ensuring the ease of implementing and embedding this asset management program, its ultimate success.

- Asset Management program is not an event, but rather a continuous process that requires constant inputs and feedback for improvement.

Finally, it is concluded that the study did achieve its objectives. The research further affirms that there is a relationship among the two propositions: (1) to have a stable plant, equipment has to be consistently available, and (2) the only way to achieve system availability is through reliable equipment.

\section{Appendix A - Research Questionnaire}

\section{Asset Management Survey}

This focus of the study is to receive feedback from senior stake-holders of capital-intensive physical assets on the main bottlenecks and challenges in implementing improvements in the field of asset management. The aim of this questionnaire is to collect this feedback in a systematic manner. Participations in the questionnaire will enable the development of a case and recommendations on successfully implementing the Asset Management principles using PAS 55 as a guideline. The format of the questionnaire is also such that it can service as a checklist for one's own asset management program.

The overview will be anonymous and not traceable to any of the individual respondents or their companies.

\section{A. Biographical Information.}

\begin{tabular}{ll}
\hline A1.Age in Years & \\
\hline $20-24$ & 1 \\
$25-34$ & 2 \\
$35-44$ & 3 \\
$45-54$ & 4 \\
55 and above & 5 \\
\hline
\end{tabular}

\begin{tabular}{ll}
\hline A2.Work experience in years & \\
\hline 5 and below & 1 \\
$6-10$ & 2 \\
$11-15$ & 3 \\
$16-20$ & 4 \\
21 and above & 5 \\
\hline
\end{tabular}

\begin{tabular}{ll}
\hline A3.Educational Level & \\
\hline Metric/NQF4 & 1 \\
Diploma & 2 \\
Degree & 3 \\
\hline
\end{tabular}

\begin{tabular}{ll}
\hline A4.Function within the business & \\
\hline Artisan (Process and Maintenance Artisans) & 1 \\
Planners (Planner/Scheduler/Planner assistants) & 2 \\
Engineers (Discipline and Reliability engineers) & 3 \\
First Line Management (Shift and Trade Managers) & 4 \\
Management (Section leader to Operations Manager) & 5 \\
\hline
\end{tabular}

B. Asset Management: General.

\begin{tabular}{lc}
$\begin{array}{l}\text { B1.What do you understand by the term "Asset Management"? Is it } \\
\text { only for Maintenance or does the term have a wider meaning? } \\
\text { (Please select one) }\end{array}$ \\
\hline $\begin{array}{l}\text { Asset Management is only for Maintenance } \\
\text { Asset Management is only for Production }\end{array}$ & 1 \\
$\begin{array}{l}\text { Asset Management is only for Maintenance and } \\
\text { Production }\end{array}$ & 3 \\
$\begin{array}{l}\text { Asset Management is for all stakeholder in the supply } \\
\text { chain (from acquisition to disposal) }\end{array}$ & 4 \\
\hline
\end{tabular}

B2. How important are the following drivers for the business in justifying investment to improve asset management processes?

\begin{tabular}{lllll} 
justifying investment to improve asset management processes? \\
\hline 1 & 2 & 3 & 4 \\
Not & Limited & Important & Very \\
relevant & Importance & & Important
\end{tabular}

Cost reduction

Improved product

quality

Improved

equipment

reliability

Improved plant

availability

Improved plant

stability

Increased

production

volume

Knowledge

management -

Improved asset

knowledge

Long term

sustainability

Legislation or

regulation

Safety

\begin{tabular}{|c|c|c|c|c|}
\hline $\begin{array}{l}\text { B3. What are the } \\
\text { Management proc }\end{array}$ & $\begin{array}{l}\text { in work } \\
\text { ses? }\end{array}$ & g level benef & of impler & ing Asset \\
\hline & 1 & 2 & 3 & 4 \\
\hline & $\begin{array}{l}\text { Not } \\
\text { relevant }\end{array}$ & $\begin{array}{l}\text { Limited } \\
\text { Importance }\end{array}$ & Important & $\begin{array}{l}\text { Very } \\
\text { Important }\end{array}$ \\
\hline $\begin{array}{l}\text { The organisational } \\
\text { learning }\end{array}$ & & & & \\
\hline
\end{tabular}




experience during
the
implementation
process
Becoming a
learning
organisation -
continuous
improvement
Bring the different
organisational
disciplines closer
together
Improved decision
making
Enhanced systems
thinking in terms
of equipment "life
cycle view"
Process
transparency

B4. What are the main challenges in improving Asset Management processes or when implementing an "Asset Management system"?

$\begin{array}{llll}1 & 2 & 3 & 4 \\ \text { Not } & \begin{array}{l}\text { Only a } \\ \text { formal }\end{array} & \begin{array}{l}\text { derabl } \\ \text { relevant }\end{array} & \begin{array}{l}\text { Signif } \\ \text { icant } \\ \text { challe }\end{array} \\ & \text { ity } & \begin{array}{l}\text { Chall } \\ \text { enge }\end{array} & \text { nge }\end{array}$

Development of the business case for the implementation Linking the Asset

Management policy and strategy to the company strategy - is there a clear company strategy?

Definition of Asset

Management policy, strategy and objectives

Getting time of the required resources

Preparation of detailed

equipment plans

Risk Management -

identification and

quantification of risks

Risk based decision making

Effective integration of

condition monitoring in Asset

Management processes

Improve Asset information

and data management

Implementation and

integration of IT support

system

Management of skills and

competencies in the

organisation

Implement organisational

changes needed to optimise

asset management

Definition of KPI's for

performance management

Process for continuous

improvement

Periodic Auditing of the Asset

Management processes

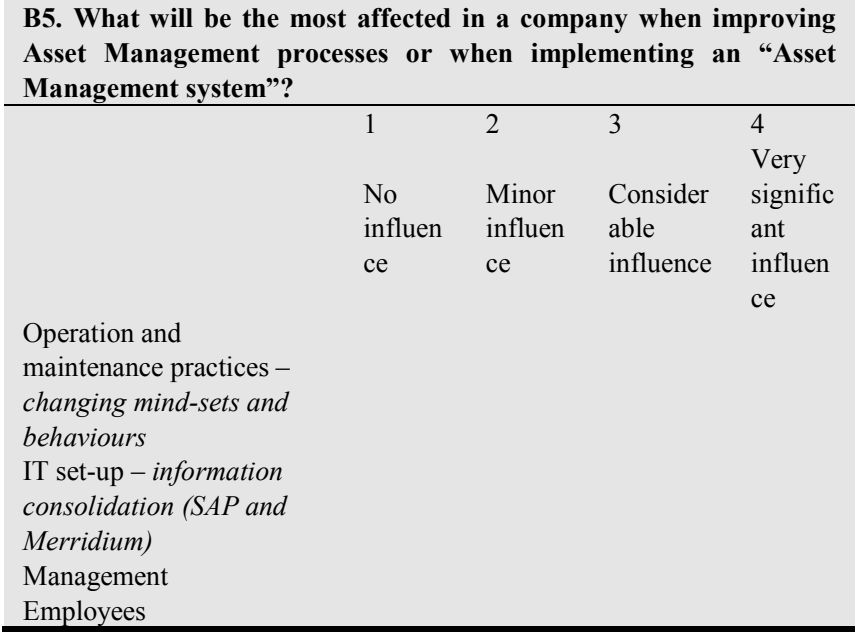

C. Asset management: Specific issues.

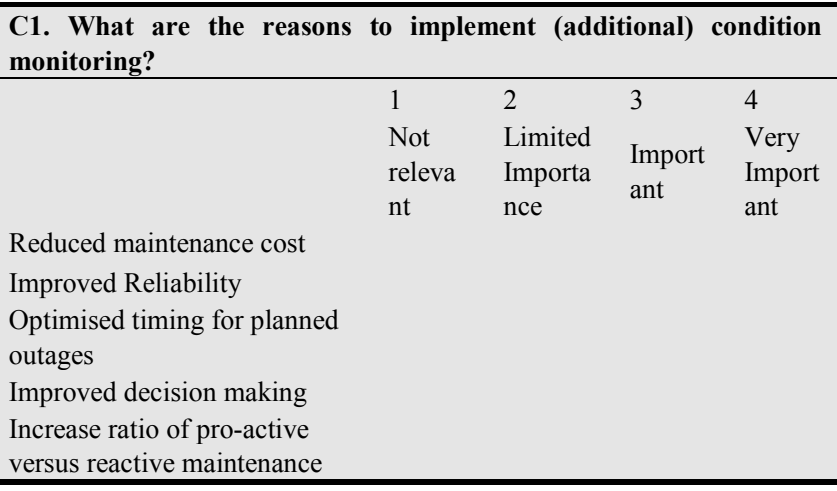

C2. How important are the following risk identification techniques to the asset management process?

$\begin{array}{lllll}1 & 2 & 3 & 4 & 5 \\ \text { No } & \text { Not } & \text { Limite } & & \text { Very } \\ \mathrm{t} & \text { releva } & \mathrm{d} & \text { Impor } & \text { Impor } \\ \text { use } & \mathrm{nt} & \text { Import } & \text { tant } & \text { tant } \\ \mathrm{d} & & \text { ance } & & \end{array}$

RAM - Reliability

Availability and

Maintainability

FME(C)A - Failure

Mode Effect

(Criticality) Assessment

HAZOP - Hazard and

Operability

RCA - Root Cause

Analysis

\begin{tabular}{llllll}
$\begin{array}{l}\text { C3. How important is following risk management techniques to the } \\
\text { asset management process? }\end{array}$ & & & & \\
\hline & 1 & 2 & 3 & 4 & 5 \\
& $\begin{array}{l}\text { Not } \\
\text { used }\end{array}$ & $\begin{array}{l}\text { Not } \\
\text { releva } \\
\text { nt }\end{array}$ & $\begin{array}{l}\text { Limited } \\
\text { Importa } \\
\text { nce }\end{array}$ & $\begin{array}{l}\text { Import } \\
\text { ant }\end{array}$ & $\begin{array}{l}\text { Very } \\
\text { Import } \\
\text { ant }\end{array}$ \\
RCM - Reliability & & & & & \\
$\begin{array}{l}\text { Centred Maintenance } \\
\text { RBI-Risk Based }\end{array}$ & & & & & \\
$\begin{array}{l}\text { Inspection } \\
\text { On-line condition } \\
\text { monitoring or early } \\
\text { warning system } \\
\text { Criticality analysis }\end{array}$ & & & & & \\
\end{tabular}




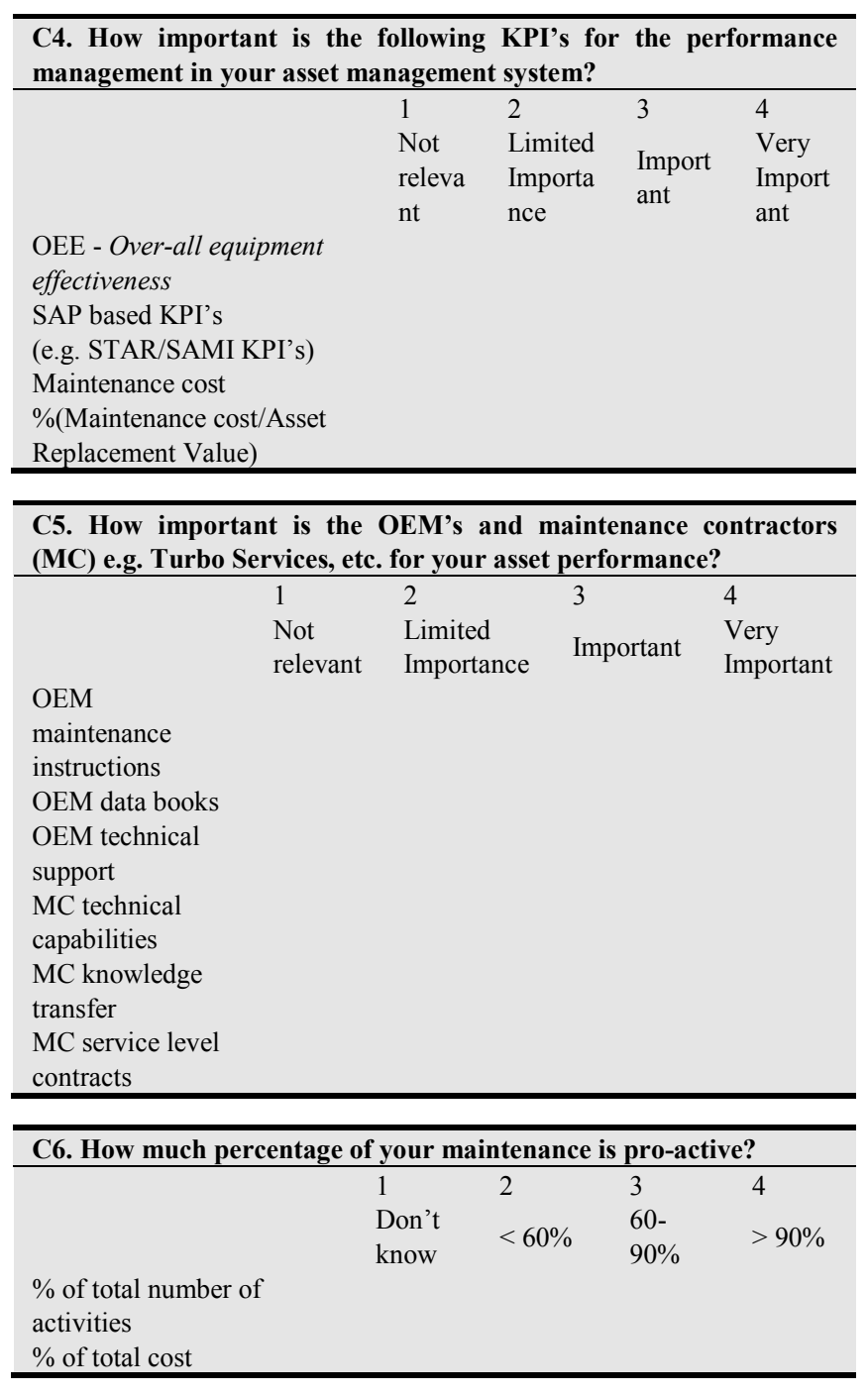

D. Asset Management: PAS 55 .

\begin{tabular}{lc}
\hline $\begin{array}{l}\text { D1. How familiar are you with PAS 55 Asset } \\
\text { specification (Mark what is true)? }\end{array}$ & 1 \\
\hline Never heard of it & 2 \\
Heard of it, but never read it & 3 \\
Read it, but don't understand everything & 4 \\
Comfortable with it & 5 \\
Work according to the specification & 6 \\
Have been assessed based on it & \\
\hline
\end{tabular}

D2. If you are familiar with PAS 55, do you think it is just a "flavour of the month"?

(mark your opinion)

Yes

No, it is here to stay

\section{Biography}

Makama Ephraim Ntlaba is a qualified engineer. He has recently completed a Master of Business Leadership (MBL) at UNISA. He works for a Petro Chemical Company as an Engineering Manager.
Ozias Ncube is a senior lecturer at University of South Africa 's Graduate School of Business Leadership (SBL) and is responsible for supply chain management and operations management. He has more than 10 years of practical experience in these areas. His research interests include but are not limited to the following: supply chain vulnerability and resilience, asset optimisation, supply chain and business strategy alignment, green procurement and humanitarian supply chains. He has presented research papers in local and international forums, mainly on supply chain management, with publications in both academic and business journals.

\section{References}

[1] British Standards Institution.2008.PAS55: Asset Management. London: British Standards Institution.

[2] Campbell, J.D. and Reyes-Picknell, J.V.2006.UPTIME: Strategies for Excellence in Maintenance Management. $2^{\text {nd }}$ ed.New York: Productivity Press.

[3] Diamantopoulos, A. and Schlegelmilch, B.B.ed.2000.Taking Fear Out of Data Analysis. Singapore: Seng Lee Press.

[4] Fiaz, R.B. and Edirisinghe, E.A.2009.'Decision Making for Predictive Maintenance in Asset Information Management' Interdisciplinary Journal of Information, Knowledge, and Management, 4: 23-36.

[5] Golafshani, N.2003.'Understanding Reliability and Validity in Qualitative Research' The Qualitative Report,8(4): 597607

[6] Hastings, N.J.A.ed.2010.Physical Asset Management. New York: Springer.

[7] Horner, R.M.W., El-Haram, M.A. \&Munns, A.K.1997.'Building maintenance strategy: a new management approach' Journal of Quality in Maintenance Engineering, 3(4): 273-280.

[8] Leedy, P.D. and Ormrod, J.E.2010. Practical Research: Planning and Design. $9^{\text {th }}$ ed. New Jersey: Pearson Education, Inc.

[9] Moubrey, J.1997.RCM II: Reliability-centred Maintenance. $2^{\text {nd }}$ ed.New York: Industrial Press, Inc.

[10] "Reliability Tips". October 2007.Maintenance Key Performance Indicators.[Blog entry].Available from: $<$ http://www.idcon.com/reliability-tips-710.html> [Accessed: 14 June 2012].

[11] Safi, S. and Mozard, S.(2004). From Reactive Maintenance To Proactive Preventive Maintenance System. Report for Covaris Pty Ltd. Unpublished.

[12] Wireman, T.2005.Developing Performance Indicators for Managing Maintenance. $2^{\text {nd }}$ ed.New York: Industrial Press, Inc. 